\section{Perfil do trabalho e acidentes de trânsito entre motociclistas de entregas em dois municípios de médio porte do Estado do Paraná, Brasil}

\author{
Work profile and traffic accidents among \\ motorcycle couriers in two medium-sized cities in \\ the State of Paraná, Brazil
}

\author{
${ }_{1}^{1}$ Departamento de \\ Fisioterapia, Universidade \\ Estadual de Londrina, \\ Londrina, Brasil. \\ 2 Departamento de Saúde \\ Coletiva, Universidade \\ Estadual de Londrina \\ Londrina, Brasil. \\ 3 Departamento de \\ Enfermagem, Universidade \\ Estadual de Maringá, \\ Maringá, Brasil. \\ Correspondência \\ S. M. Andrade \\ Departamento de Saúde \\ Coletiva, Centro de Ciências \\ da Saúde, Universidade \\ Estadual de Londrina. \\ Rua Sergipe 1639, apto. 201, \\ Londrina, $P R$ \\ 86020-330, Brasil. \\ semaffei@sercomtel.com.br
}

\begin{abstract}
This cross-sectional study focused on motorcycle couriers (work profile, work conditions, and traffic accidents) in Londrina and Maringá, Paraná State, Brazil. Data were collected from self-completed questionnaires in 2005-2006. In Londrina and Maringá, respectively, 377 and 500 motorcycle couriers completed the questionnaire, with mean ages of 28 and 29 years. Londrina showed a higher proportion of couriers that earned per delivery, worked both day and night or on night shifts only, and who worked more than 10 hours a day $(p<0.05)$. Despite greater exposure to hazardous work and traffic conditions in Londrina, there was no significant difference in the accident rates during the 12 months prior to the survey in Londrina and Maringá (2.89 and 2.80 per 100 person-months, respectively). The study detected precarious work conditions, high exposure to hazardous traffic conditions, and high accident rates among motorcycle couriers.
\end{abstract}

Motorcycles; Traffic Accidents; Occupational Accidents
Daniela Wosiack da Silva 1 Selma Maffei de Andrade 2 Darli Antonio Soares 2 Dorotéia Fátima Pelissari de Paula Soares 3 Thais Aidar de Freitas Mathias 3

\section{Introdução}

No Brasil, nos últimos anos, observa-se o crescimento da frota de motocicletas e de sua utilização nos serviços de entrega de mercadorias, o que pode contribuir para o aumento de acidentes envolvendo motociclistas no país 1 . Os motociclistas que realizam entregas de produtos ou prestam pequenos serviços, popularmente conhecidos como motoboys, atendem às necessidades de rapidez e agilidade da sociedade contemporânea de consumo, e sua presença e tendência de crescimento parecem irreversíveis a curto e médio prazo 2 .

A crescente utilização da motocicleta como instrumento de trabalho pode ser explicada, talvez, pelo aumento do desemprego observado entre jovens no Brasil na última década. Durante os anos 1990, com a estabilização da inflação e queda do nível de atividade econômica, houve aumento da taxa de desemprego, especialmente entre os trabalhadores mais jovens ${ }^{3}$. Contribuíram ainda para esse quadro as privatizações e inovações tecnológicas e a abertura comercial, resultando no aumento da informalidade e da flexibilização das relações de trabalho ${ }^{4,5}$.

Estudos realizados em Londrina e em Maringá, Estado do Paraná, apontam os motociclistas como as principais vítimas de acidentes de trânsito nos dois municípios. Em Londrina, em 1996, os motociclistas corresponderam a $44,4 \%$ das 3.643 vítimas 6 . Outra investigação, no mesmo 
município, analisando o período compreendido entre 1997 e 2000, traz os motociclistas como as principais vítimas do trânsito atendidas por serviço de atenção pré-hospitalar em todos os anos, com valores sempre superiores a $40 \% 7$. Em Maringá, estudo detectou que os motociclistas foram o principal tipo de vítima dos acidentes de trânsito ocorridos em 2000, o que equivaleu a $38,6 \%$ das 3.468 vítimas identificadas 8 .

A utilização da motocicleta no mercado formal ou informal de trabalho, especialmente em serviços de tele-entrega de mercadorias e documentos (motoboys) ou transporte de passageiros (mototáxis), é referida por diversos autores como possível causa para o aumento do número de vítimas motociclistas 1,6,9,10.

A ocupação motoboy consta na Classificação Brasileira de Ocupações de 2002, do Ministério do Trabalho e Emprego (http:/ / www.mtecbo.gov.br/ busca/descricao.asp?codigo $=5191-10$, acessado em 29/Jun/2006), sendo descrita como "motociclista no transporte de documentos e pequenos volumes" (código 5191-10). No entanto, ela ainda não está regulamentada no país, o que pode contribuir para a informalidade das relações trabalhistas e para a precariedade das condições de trabalho, que favorecem, ao menos em parte, a ocorrência de acidentes de transporte envolvendo essa população. Algumas cidades brasileiras regulamentaram a profissão motoboy por meio de decretos municipais, como é o caso de São Paulo ${ }^{11}$ e João Pessoa (Paraíba) 12. Em Londrina e em Maringá, porém, não há regulamentação para esse serviço.

Os motoboys representam uma população de grande risco de envolvimento em acidentes de trânsito devido às constantes exigências inerentes ao seu exercício profissional. Observa-se, no entanto, que esse é um assunto pouco explorado no Brasil, com raras publicações sobre o tema.

O objetivo deste estudo foi o de analisar, nos Municípios de Londrina e Maringá, o perfil de motociclistas que fazem entregas ou realizam pequenos serviços (motoboys), suas condições de trabalho, situações de risco e a ocorrência de acidentes de trânsito.

\section{Metodologia}

Trata-se de um estudo transversal, tendo como unidade de análise motoboys de Londrina e Maringá, municípios localizados no norte do Paraná com populações projetadas, em 2006, de 495.698 e 324.395 habitantes, respectivamente (DATASUS. População Residente - Paraná. http://tabnet.datasus.gov.br/cgi/tabcgi.exe?ibge/ cnv/poppr.def, acessado em 12/Set/2007). Para determinar os tipos de empresa que mais utilizam os serviços de entrega, foi necessária observação prévia nas principais vias públicas dos dois municípios durante um período de três meses anteriores à realização da pesquisa. Após a determinação dos principais tipos de empresa, o número de motoboys foi estimado por meio de consultas telefônicas aos sete principais tipos de empresas identificadas (restaurantes/lanchonetes/pizzarias, farmácias, papelarias/copiadoras, empresas de tintas, de distribuição de gás, água e especializadas em entregas), buscando-se estimar o número de motoboys atuantes em cada cidade.

Em Londrina, foram identificados $1.087 \mathrm{mo}$ toboys atuantes em 410 empresas. O tamanho mínimo da amostra foi calculado por meio do programa Epi Info 6.04d (Centers for Disease Control and Prevention, Atlanta, Estados Unidos). Considerou-se, para tanto, uma prevalência de 50\%, que é a que possibilita o maior tamanho amostral possível, um erro máximo de 3,5\% e intervalo de 95\% de confiança (IC95\%). Dessa forma, o tamanho mínimo da amostra foi calculado em 456 motoboys, número ao qual foram acrescidos $10 \%$ para possíveis perdas, totalizando 502 .

Para garantir a proporcionalidade do número de motoboys por tipos de empresa e por períodos de trabalho (matutino, vespertino ou noturno), as empresas foram ordenadas por tipo e, dentro de cada grupo, por número de motoboys. Considerando que a amostra mínima calculada aproximava-se dos $50 \%$ do universo identificado, foi realizada seleção sistemática das empresas, com constante de sistematização igual a dois, para a qual se sorteou o número dois. Foram, assim, selecionadas 205 empresas e 531 motoboys. No entanto, essa forma de seleção excluiu uma empresa de entregas com 96 motoboys, maior número entre todas. Assim, visando melhorar a distribuição proporcional do número de motoboys, a empresa foi incluída, sendo selecionados, aleatoriamente, $50 \%$ dos motoboys atuantes nela, totalizando, então, 579 motoboys amostrados em Londrina.

Em Maringá, foram identificados $580 \mathrm{mo}$ toboys em 224 empresas, o que permitiu, considerando as condições de suporte à pesquisa, que todos fossem incluídos na população a ser investigada.

A coleta de dados, feita por profissionais e estudantes de nível superior previamente treinados, ocorreu de setembro a novembro de 2005 em Londrina e, em Maringá, de junho a dezembro de 2006, nos próprios locais de trabalho dos motoboys ou em outros definidos após contato telefônico. Foi utilizado um questionário autoaplicável, contendo questões fechadas e algumas 
abertas. Esse instrumento foi desenvolvido após diversas etapas visando ao seu aprimoramento - grupo focal com motoboys, revisão por cinco professores do programa de pós-graduação stricto sensu em Saúde Coletiva da Universidade Estadual de Londrina (UEL) e estudo piloto com 25 motoboys -, com a finalidade de ser compreensível para os pesquisados, mesmo para os de baixa escolaridade, e rápido para responder, devido à demanda de trabalho desses profissionais. Com o objetivo de reduzir perdas, foram realizadas até cinco visitas à mesma empresa nos três períodos do dia.

Para o processamento eletrônico dos dados, foi utilizado o programa Epi Info 6.04d. Foram realizadas dupla digitação, comparação e correções quando observadas inconsistências entre os bancos, após consulta aos questionários respondidos.

As variáveis de estudo foram agrupadas da seguinte forma: variáveis relacionadas à caracterização dos motoboys (sexo, idade, escolaridade, tempo de experiência como condutor de motocicleta), variáveis relacionadas ao trabalho dos motoboys (tipo de empresa de atuação, tempo de atuação profissional, tipo de remuneração, período do dia trabalhado, alternância de turnos de trabalho e número de horas trabalhadas diariamente) e variáveis relacionadas a situações de risco no trânsito (tempo de uso das motocicletas e seu estado de conservação, hábito de dirigir com a luz do veículo acesa durante o dia e durante a noite, modelo de capacete e sua correta utilização, direção da motocicleta ainda que bastante cansados, consumo de álcool previamente à direção, uso de celular ou rádio comunicador quando em trânsito e adoção de altas velocidades - acima de $80 \mathrm{~km} / \mathrm{h}$ - em ruas). Foi, ainda, analisada a taxa de acidentes de trânsito ocorridos no trabalho e no trabalho/lazer (total de acidentes) nos últimos 12 meses nos dois municípios.

Para comparação dos resultados nos dois municípios, foi utilizado o teste do qui-quadrado com correção de Yates ou o teste exato de Fisher, quando necessário, sendo adotado um nível de significância de 0,05. Considerando que a exposição a acidentes de trabalho ou a acidentes ocorridos no lazer e no trabalho (total de acidentes) nos 12 meses anteriores à realização da pesquisa poderia variar de acordo com o tempo de atuação profissional de cada motoboy ou de acordo com o tempo de experiência como condutor de motocicleta (de dias ao ano completo), houve a transformação do denominador em pessoasmês. Foram calculadas as taxas de acidentes e a razão entre essas taxas (Londrina/Maringá) para acidentes durante o trabalho e durante o lazer e trabalho. Para analisar diferenças entre essas taxas, foram usados o IC95\% e o valor de p (teste exato bicaudal), calculados por meio do programa Epi Info 6.04d.

Esta pesquisa faz parte do estudo Acidentes e Violências no Paraná: Magnitude, Tendência, Fatores Associados, Seqüelas e Gastos Hospitalares, aprovado pelo Comitê de Ética em Pesquisa da UEL (parecer 287/04). Os motoboys, ao serem abordados para a aplicação do questionário, foram esclarecidos dos objetivos da pesquisa e responderam ao questionário após leitura do Termo de Consentimento Livre e Esclarecido e de concordarem em participar do estudo. Os questionários foram colocados em uma urna lacrada visando à garantia de anonimato dos participantes.

\section{Resultados}

Em Londrina, durante a coleta de dados, ocorrida seis meses após o levantamento do número de empresas e de motoboys, observou-se que, das empresas amostradas, algumas haviam fechado e outras já não empregavam mais esses trabalhadores, havendo, portanto, redução da amostra de 206 para 167 empresas e de 579 para $428 \mathrm{mo}$ toboys, ou seja, respectivamente, $81,1 \%$ e $73,9 \%$ das empresas e motoboys previstos na amostra. Desses 428 motoboys, constatou-se que 35 trabalhavam em mais de uma empresa sorteada. Dessa forma, 393 compuseram a amostra.

Foram entrevistados 377 motoboys (95,9\%). Houve perda de 16, sendo 13 devido à recusa de estabelecimentos em participar da pesquisa, dois por recusas de motoboys e um por afastamento do trabalho devido a um acidente de trânsito.

Em Maringá, durante a pesquisa de campo ocorrida quatro meses após o estudo exploratório, observou-se, também, redução da população de pesquisa de 224 para 179 empresas e de 580 para 516 motoboys, ou seja, 79,9\% e $89 \%$, respectivamente. Desses, dez motoboys trabalhavam em mais de uma empresa sorteada. Assim, a amostra final de Maringá foi de 506, sendo entrevistados $500(98,8 \%)$. Houve perda de seis trabalhadores, quatro devido à recusa de estabelecimentos em participar da pesquisa e dois por recusas de motoboys em participar da pesquisa.

Na Tabela 1, podem ser observados dados referentes a características da população pesquisada, com resultados semelhantes para os municípios em análise. Houve predomínio absoluto do sexo masculino na profissão. A média de idade, em Londrina, foi de 28 anos (desvio-padrão $\mathrm{DP}=7,5$ anos) e, em Maringá, de 29 anos (DP = 8,5 anos). Em Londrina, a maior parte dos motoboys tinha entre 18 e 24 anos (43\%) e, em Maringá, entre 25 e 34 anos (41,6\%). Mais de $70 \%$ 
Caracterização dos motoboys atuantes em Londrina (2005) e em Maringá (2006), Paraná, Brasil.

\begin{tabular}{|c|c|c|c|c|c|}
\hline \multirow[t]{2}{*}{ Variáveis } & \multicolumn{2}{|c|}{ Londrina $(n=377)$} & \multicolumn{2}{|c|}{ Maringá $(n=500)$} & \multirow[t]{2}{*}{ Valor de $p$} \\
\hline & $\mathrm{n}$ & $\%$ & $\mathrm{n}$ & $\%$ & \\
\hline \multicolumn{6}{|l|}{ Sexo } \\
\hline Masculino & 376 & 99,7 & 498 & 99,6 & $\sim 1,000$ * \\
\hline Feminino & 1 & 0,3 & 2 & 0,4 & \\
\hline \multicolumn{6}{|l|}{ Idade (anos) } \\
\hline $18-24$ & 162 & 43,0 & 183 & 36,6 & 0,152 \\
\hline $25-34$ & 138 & 36,6 & 208 & 41,6 & \\
\hline 35 ou + & 77 & 20,4 & 109 & 21,8 & \\
\hline \multicolumn{6}{|c|}{ Escolaridade (anos) ** } \\
\hline$<8$ & 62 & 16,6 & 61 & 12,3 & 0,136 \\
\hline $8-11$ & 298 & 79,9 & 412 & 82,9 & \\
\hline 12 ou + & 13 & 3,5 & 24 & 4,8 & \\
\hline \multicolumn{6}{|c|}{ Tempo de direção (anos) } \\
\hline$<5$ & 86 & 22,8 & 130 & 26,0 & 0,554 \\
\hline $5-9$ & 119 & 31,6 & 152 & 30,4 & \\
\hline 10 ou + & 172 & 45,6 & 218 & 43,6 & \\
\hline
\end{tabular}

* Teste exato de Fisher;

** Questão respondida por 373 motoboys em Londrina e por 497 motoboys em Maringá.

tinham tempo de experiência como condutor de motocicleta superior a 5 anos (Londrina: média = 10 anos; $\mathrm{DP}=6,4$ anos; Maringá: média $=9$ anos; $\mathrm{DP}=6,8$ anos).

Quanto ao tipo de empresa de atuação, a diferença se mostrou significativa entre os motoboys nos municípios estudados. Em Londrina, os motoboys atuavam predominantemente em restaurantes/lanchonetes/pizzarias (48,3\%). Em Maringá, os principais tipos de empresas foram restaurantes/lanchonetes/pizzarias, empresas de entrega e farmácias/drogarias, com percentuais semelhantes (Tabela 2).

Também foram encontradas diferenças significativas entre os motoboys atuantes nos dois municípios em relação ao tipo de remuneração, ao período do dia em que trabalhavam, à alternância de turnos de trabalho e ao número de horas trabalhadas, conforme pode ser observado na Tabela 3. Houve maior proporção de trabalhadores, em Londrina, que relataram ganhar por produtividade, trabalhar durante os períodos do dia e da noite ou apenas à noite e com jornada diária superior a dez horas. O tempo de atuação profissional dos motoboys, em ambos os municípios, foi bastante semelhante. Mais de $70 \%$ dos profissionais entrevistados referiram tempo de atuação superior a dois anos.

Os motoboys relataram uma média de tempo de uso da motocicleta de 5 anos em Londrina
(DP $=5,7$ anos) e de 6 anos em Maringá (DP = 5,5 anos). A maioria dos veículos apresentava-se, segundo os pesquisados, com a parte elétrica e pneus em bom estado de conservação (percentuais próximos a 100\%).

O hábito de dirigir com a luz acesa foi relatado pela maioria dos motoboys atuantes em Londrina $(100 \%$ durante a noite e $98,9 \%$ durante o dia) e em Maringá (99,6\% durante a noite e 96,3\% durante o dia).

Na Tabela 4, podem ser observadas diferenças significativas entre os motoboys em relação ao tipo de capacete utilizado e a situações de risco para acidentes no trânsito, com maior proporção de condutores, em Londrina, que utilizam o modelo de capacete sem proteção para a mandíbula ("aberto"), dirigem a motocicleta mesmo estando bastante cansados, e que adotam altas velocidades (acima de $80 \mathrm{~km} / \mathrm{h}$ ) em ruas da cidade. Por outro lado, resultados semelhantes foram observados nas duas cidades no que se refere ao relato de utilização de celular ou rádio comunicador quando em trânsito e ao consumo de bebidas alcoólicas previamente à direção da motocicleta. De acordo com os motoboys, o consumo de álcool se deu, predominantemente, em momentos de lazer e não durante o exercício profissional. A ingestão de bebidas alcoólicas durante o trabalho foi relatada por 4 dos 128 motoboys que referiram consumo de álcool antes de dirigir a motocicleta 
Distribuição dos motoboys atuantes em Londrina (2005) e Maringá (2006), Paraná, Brasil, segundo o tipo de empresa de atuação.

\begin{tabular}{|c|c|c|c|c|c|}
\hline \multirow[t]{2}{*}{ Tipo de empresa } & \multicolumn{2}{|c|}{ Londrina $(n=377)$} & \multicolumn{2}{|c|}{ Maringá ( $n=500$ ) } & \multirow[t]{2}{*}{ Valor de $p$ ** } \\
\hline & $n$ * & $\%$ & $n$ * & $\%$ & \\
\hline Restaurantes/Lanchonetes/Pizzarias & 182 & 48,3 & 142 & 28,4 & $<0,001$ \\
\hline Farmácias/Drogarias & 101 & 26,8 & 122 & 24,4 & \\
\hline Empresas de entregas & 90 & 23,9 & 130 & 26,0 & \\
\hline Empresas que entregam água & 43 & 11,4 & 61 & 12,2 & \\
\hline Lojas de tintas & 26 & 6,9 & 56 & 11,2 & \\
\hline Empresas que entregam gás & 24 & 6,4 & 54 & 10,8 & \\
\hline Papelarias/Copiadoras & 15 & 4,0 & 39 & 7,8 & \\
\hline Outros & 44 & 11,7 & 50 & 10,0 & \\
\hline
\end{tabular}

* Admite mais de uma resposta;

** Graus de liberdade $=7$.

Tabela 3

Distribuição dos motoboys atuantes em Londrina (2005) e Maringá (2006), Paraná, Brasil, segundo variáveis relacionadas ao trabalho.

\begin{tabular}{|c|c|c|c|c|c|}
\hline \multirow[t]{2}{*}{ Variáveis } & \multicolumn{2}{|c|}{ Londrina $(n=377)$} & \multicolumn{2}{|c|}{ Maringá $(n=500)$} & \multirow[t]{2}{*}{ Valor de $p$} \\
\hline & $\mathbf{n}$ & $\%$ & $\mathbf{n}$ & $\%$ & \\
\hline \multicolumn{6}{|c|}{ Tempo de atuação (anos) * } \\
\hline$<2$ & 97 & 25,7 & 141 & 28,3 & 0,195 \\
\hline $2-4$ & 111 & 29,4 & 164 & 32,9 & \\
\hline 5 ou + & 169 & 44,9 & 193 & 38,8 & \\
\hline \multicolumn{6}{|c|}{ Tipo de remuneração ** } \\
\hline Salário fixo & 128 & 34,0 & 261 & 52,3 & $<0,001$ \\
\hline Produtividade & 249 & 66,0 & 238 & 47,7 & \\
\hline \multicolumn{6}{|c|}{ Período trabalhado ** } \\
\hline Dia e noite & 175 & 46,4 & 168 & 33,7 & $<0,001$ \\
\hline Dia & 158 & 41,9 & 297 & 59,5 & \\
\hline Noite & 44 & 11,7 & 34 & 6,8 & \\
\hline \multicolumn{6}{|c|}{ Alternância de turnos ** } \\
\hline Sim & 137 & 36,3 & 118 & 23,6 & $<0,001$ \\
\hline Não & 240 & 63,7 & 381 & 76,4 & \\
\hline \multicolumn{6}{|c|}{ Horas trabalhadas (por dia) } \\
\hline $10 e+$ & 160 & 42,4 & 170 & 34,0 & 0,013 \\
\hline$<10$ & 217 & 57,6 & 330 & 66,0 & \\
\hline
\end{tabular}

* Questão respondida por 498 motoboys em Maringá;

** Questão respondida por 499 motoboys em Maringá.

em Londrina e, em Maringá, por 13 dos 196 que relataram sua ingestão.

Foi alta a proporção de motoboys que relatou o correto afivelamento do capacete em Londrina (97,6\%) e em Maringá (96,2\%). Foi elevada, também, a proporção que referiu utilizar capacete com o selo de qualidade do Instituto Nacional de Metrologia, Normalização e Qualidade Indus- trial (INMETRO): 82,8\% em Londrina e 88,1\% em Maringá.

As taxas de acidentes de trânsito relatados durante o exercício profissional em Londrina e Maringá foram, respectivamente, de 2,89 e de 2,80 por 100 pessoas-mês, e, para acidentes durante o lazer ou trabalho (total de acidentes), de 3,28 e de 3,05 por 100 pessoas-mês, respectivamente. 
Distribuição dos motoboys atuantes em Londrina (2005) e Maringá (2006), Paraná, Brasil, segundo o tipo de capacete utilizado e situações de risco no trânsito.

\begin{tabular}{|c|c|c|c|c|c|}
\hline \multirow[t]{2}{*}{ Variáveis } & \multicolumn{2}{|c|}{ Londrina $(n=377)$} & \multicolumn{2}{|c|}{ Maringá $(n=500)$} & \multirow[t]{2}{*}{ Valor de $\mathrm{p}$} \\
\hline & n & $\%$ & n & $\%$ & \\
\hline \multicolumn{6}{|c|}{ Tipo de capacete utilizado } \\
\hline Aberto & 199 & 52,8 & 167 & 33,4 & $<0,001$ \\
\hline Fechado & 158 & 41,9 & 326 & 65,2 & \\
\hline Ambos os modelos & 20 & 5,3 & 7 & 1,4 & \\
\hline \multicolumn{6}{|l|}{ Dirigir cansado * } \\
\hline Sim & 318 & 84,4 & 356 & 71,4 & $<0,001$ \\
\hline Não & 59 & 15,6 & 143 & 28,6 & \\
\hline \multicolumn{6}{|c|}{ Consumo prévio de álcool } \\
\hline $\operatorname{Sim}$ & 128 & 34,0 & 196 & 39,2 & 0,128 \\
\hline Não & 249 & 66,0 & 304 & 60,8 & \\
\hline \multicolumn{6}{|c|}{ Uso de celular/rádio comunicador em trânsito } \\
\hline $\operatorname{Sim}$ & 90 & 23,9 & 109 & 21,8 & 0,520 \\
\hline Não & 287 & 76,1 & 391 & 78,2 & \\
\hline \multicolumn{6}{|c|}{ Altas velocidades em ruas ** } \\
\hline Sim & 108 & 28,6 & 102 & 20,6 & 0,007 \\
\hline Não & 269 & 71,4 & 394 & 79,4 & \\
\hline
\end{tabular}

* Questão respondida por 499 motoboys em Maringá;

** Acima de 80km/h. Questão respondida por 496 motoboys em Maringá.

Não foram encontradas diferenças significativas no relato de ocorrência de acidentes de trânsito durante o trabalho nos 12 meses anteriores à realização da pesquisa nos dois municípios (razão entre as taxas Londrina/Maringá = 1,03 [IC95\% = 0,81-1,31]; $p=0,81$ ) ou para os acidentes ocorridos no lazer e no trabalho (razão entre as taxas = 1,07 [IC95\% = 0,86-1,33]; $\mathrm{p}=0,54$ ).

\section{Discussão}

O presente estudo aborda um tema praticamente não explorado na literatura científica brasileira, sendo de conhecimento dos autores desta pesquisa apenas estudos com metodologia qualitativa realizados nos Estados de Minas Gerais 13,14 e do Rio Grande do Sul 15,16. Portanto, há certa dificuldade nas comparações diretas com outros trabalhos.

Observou-se excelente receptividade dos motoboys à pesquisa e baixa taxa de não resposta. As perdas foram mínimas e ocorreram principalmente devido à recusa de empregadores em permitir que os motoboys participassem do estudo. É possível que essas empresas apresentem piores condições de trabalho, pois, em um dos estabelecimentos sorteados, houve indícios, percebidos no contato do entrevistador com o gerente, de que precárias condições de trabalho e informalidade foram fatores que levaram à recusa.

O fato de a maior parte dos motoboys atuantes nos municípios de análise ser jovem pode indicar sua dificuldade em conseguir emprego em outros setores que exigem maior qualificação ou experiência profissional, apesar de mais de $80 \%$ dos motoboys apresentarem boa escolaridade (8 anos ou mais de estudo), em comparação ao padrão de escolaridade brasileira. De acordo com estimativas de 2003 , apenas $46,36 \%$ da população com 15 anos ou mais têm oito ou mais anos de estudo (DATASUS. Indicadores e Dados Básicos - Brasil - 2004. http:/ / tabnet.datasus.gov. br/cgi/tabcgi.exe?idb2004/b02.def, acessado em 06/Jul/2006). Nos grupos etários de 18 a 20 anos e de 21 a 23 anos, a taxa de desemprego cresceu, de 1990 a 2002 , de $9,72 \%$ para $24,57 \%$ e de $7,64 \%$ para $17,10 \%$, respectivamente, enquanto, para os demais grupos etários, essa taxa permaneceu abaixo dos $6 \%$ no mesmo período ${ }^{3}$. Esses dados reforçam a afirmação de Veronese 15 , segundo a qual a profissão motoboy surge, no Brasil, como uma solução para atenuar o problema do desemprego na falta de melhores opções de trabalho.

Outro estudo, realizado em Minas Gerais, revela que as empresas que contratam serviços de motoboys preferem profissionais mais jovens, com idade entre 18 e 25 anos, pois acreditam que, 
nessa faixa etária, eles são mais produtivos 13. O fato de a maior parte dos motoboys ser jovem pode ser também explicado pelo maior espírito de aventura, próprio da idade, o que os leva a assumir mais facilmente condições de risco, inclusive no trabalho.

Neste estudo, mais de $70 \%$ dos motoboys relataram tempo de experiência como condutor de motocicleta superior a cinco anos e tempo de atuação profissional superior a dois anos. Isso, aliado ao fato de grande parte dos pesquisados (42,4\% em Londrina e 34\% em Maringá) ter relatado trabalhar mais de dez horas diárias, indica que o que era antes um "bico" passa a ser profissão, com grande dedicação de tempo ao trabalho.

Em ambas as cidades, foram relatadas condições de trabalho adversas e exposição a situações de risco para a ocorrência de acidentes de trânsito, como ganho por produtividade, longas jornadas de trabalho, hábito de dirigir a motocicleta ainda que bastante cansados, alternância de turnos de trabalho e adoção de altas velocidades em ruas. No entanto, os motoboys atuantes em Londrina relataram piores condições de trabalho e maior exposição a situações de risco para a ocorrência de acidentes de trânsito do que os de Maringá.

Foram observadas diferenças importantes entre os dois municípios em relação à distribuição do tipo de empresa empregadora desses trabalhadores. Em Londrina, a maior parte dos motoboys relatou os restaurantes/lanchonetes/ pizzarias como o principal tipo de empresa que os contratava (48,3\%). Em Maringá, observaramse percentuais semelhantes de atuação em restaurantes/lanchonetes/pizzarias, empresas de entregas e farmácias $(28,4 \%, 26 \%$ e $24,4 \%$, respectivamente). O fato de a maioria dos motoboys de Londrina atuar em restaurantes/lanchonetes/ pizzarias indica, possivelmente, hábito mais freqüente dos moradores dessa cidade de solicitarem refeições prontas, e pode ter contribuído para que uma maior proporção desses profissionais referisse trabalho nos períodos da noite, jornadas de trabalho superiores a dez horas diárias e, conseqüentemente, que um maior número relatasse ter trabalhado ainda que bastante cansado, quando comparados aos de Maringá.

Estudos realizados com motoboys de Minas Gerais 14 e do Rio Grande do Sul 15 apontam a pressão exercida por clientes como fator determinante para a organização do trabalho imposta pelas empresas que contratam os serviços dessa categoria, o que os submete à elevada densidade de trabalho. As exigências de pontualidade, presteza e confiabilidade são o principal fator para adoção de comportamentos de risco no trânsito.
Ainda segundo os autores, aliada à pressão por entregas rápidas, a remuneração por produtividade aparece como fator responsável pela adoção de práticas de direção nem sempre seguras na entrega de mercadorias ou produtos. Os motoboys entrevistados por Veronese 15 , em Porto Alegre, revelaram que, em uma escala de valores, a segurança acaba ocupando posição secundária em relação ao cumprimento das demandas de trabalho e da remuneração por produtividade. No presente estudo, observou-se que, em Londrina, em cerca de dois terços dos casos, a remuneração dos motoboys estava relacionada à quantidade de entregas feitas, enquanto, em Maringá, quase a metade dos entrevistados referiu essa modalidade de pagamento, o que pode contribuir para a adoção de comportamentos de risco no trânsito e, conseqüentemente, para a ocorrência de acidentes.

Nesta pesquisa, os motoboys, em sua maioria (84,4\% em Londrina e 71,4\% em Maringá), referiram ter trabalhado ainda que bastante cansados, sendo essa a principal situação de risco no trânsito reportada pelos trabalhadores pesquisados. Esses achados diferem dos encontrados em Dunedin, Nova Zelândia 17, onde apenas 5\% dos jovens de 18 anos pesquisados relataram ter dirigido a motocicleta mesmo estando bastante cansados, o que pode ser explicado pelas diferenças no uso predominante da motocicleta (trabalho, no presente caso, e lazer naquele país). Os motoboys atuantes em Porto Alegre referiram o fator "cansaço", causado pela sobrecarga de trabalho, como provocador de acidentes por falhas humanas, ocorrendo diminuição dos reflexos e da atenção exigida no trânsito 15

Grande parte dos motoboys relatou, no presente estudo, alternância de turnos e jornadas de trabalho superiores a dez horas diárias. Esses resultados corroboram os de outro estudo de abordagem qualitativa, o qual já apontou que os motoboys se submetem a longas jornadas de trabalho e realizam horas extras para compensar a baixa remuneração obtida, tendo sido relatadas, por muitos deles, jornadas de trabalho de 13 a 15 horas diárias 13 .

A informalidade nas relações de trabalho também pode contribuir para a adoção de estratégias, pelos trabalhadores, que visem ao aumento da produtividade, porém com prejuízos à sua saúde e à sua qualidade de vida e, no caso da população pesquisada, com possível aumento do risco de acidentes de trânsito. Estudo realizado na Austrália 18, com empregados de hotéis, detectou que funcionários sem vínculo empregatício tendem a apresentar longas jornadas de trabalho, combinadas com baixa previsibilidade e pouco controle sobre o processo laboral, acar- 
retando-lhes maior conflito entre trabalho e vida pessoal e problemas decorrentes desse conflito, como distúrbios do sono, cansaço, desestruturação dos regimes alimentar e de exercícios. Precárias condições de trabalho são observadas, em geral, entre trabalhadores de categorias profissionais pouco organizadas, como é o caso dos motoboys, e a falta de regulamentação profissional, aliada à grande oferta de mão-de-obra, contribui para a manutenção das más condições de trabalho a que são submetidos.

No presente estudo, foi relatada adoção de altas velocidades em ruas por um número considerável de motoboys, sendo maior a proporção de relato dessa prática em Londrina. É possível que essa constatação se deva à maior proporção de empregos em restaurantes/pizzarias/lanchonetes nessa cidade. Isso demanda a entrega de refeições ainda quentes, contribuindo para o aumento de velocidade nos percursos. Esse fato é preocupante, pois as ruas, em geral, apresentam grande fluxo de pedestres e veículos, além de oferecerem menor visibilidade aos motoristas. Motoboys atuantes em Porto Alegre referiram, em sua maioria, adotar freqüentemente a velocidade de $80 \mathrm{~km} / \mathrm{h}$ entre uma entrega e outra, e que o número de entregas a serem realizadas provoca o aumento da velocidade 15,16.

A associação entre direção em alta velocidade e risco de acidente é bem documentada na literatura científica. Por exemplo, autores de um estudo realizado na Espanha encontraram forte associação entre a direção de motocicletas em altas velocidades (acima do limite de velocidade permitido) e o risco de colisões 19. Outra investigação, na China, também detectou forte associação entre adoção de altas velocidades e ocorrência de acidentes de trânsito envolvendo motociclistas, sendo observada maior gravidade dos acidentes com o aumento da velocidade 20 . Em Londrina, pesquisa realizada em 1996 encontrou alta proporção de acidentes ocorridos em avenidas e rodovias do perímetro urbano do município, vias públicas propícias para o desenvolvimento de velocidades excessivas 21 . Em Maringá, estudo aponta alta taxa de óbitos por acidentes de trânsito ocorridos em avenidas do município 22

Foram elevados os índices de referência ao uso de capacete sem proteção para a mandíbula, sendo esse maior em Londrina $(52,8 \%)$ do que em Maringá (33,4\%). Uma possível explicação para esse fato é que os motoboys têm necessidade de se apresentar nos locais de entrega e, utilizando o capacete "aberto", não é necessário retirá-lo ao adentrar estabelecimentos comerciais e residências. É possível que as piores condições de trabalho relatadas por motoboys atuantes em Londrina e a necessidade de maior rapidez na realização de entregas influenciem a escolha do modelo de capacete, o que é preocupante, pois esse modelo não protege adequadamente a face, especialmente a mandíbula, em caso de acidente. Torna-se imprescindível, assim, a adoção de estratégias educativas e legislativas que visem ao aumento do uso de equipamento que confira maior proteção a esse segmento corpóreo.

No presente estudo, apesar da maior exposição dos motoboys atuantes em Londrina a más condições de trabalho e a situações de risco, não foi observada diferença significativa no relato de ocorrência de acidentes de trânsito entre os trabalhadores das duas cidades, o que indica que outras variáveis podem influenciar nas taxas de ocorrência de acidentes envolvendo essa população. É importante salientar que, neste estudo, foi realizada uma estimativa mínima dos acidentes envolvendo motoboys, pois a taxa de acidentes poderia ser maior se os motoboys afastados do trabalho por acidentes de trânsito tivessem participado da pesquisa. Outro fator limitante é que as informações foram obtidas por meio de relatos de motoboys, o que pode resultar em viés de memória.

Este estudo evidenciou precárias condições de trabalho, alta exposição de motoboys a situações de risco no trânsito e elevada taxa de acidentes envolvendo esses profissionais. Tornamse necessárias, dessa forma, regulamentação da profissão e maior fiscalização das empresas que oferecem serviços prestados por motoboys nos dois municípios, visando à redução dos riscos a que esses profissionais estão expostos. 


\section{Resumo}

Com o objetivo de analisar o perfil de motociclistas que fazem entregas (conhecidos como motoboys) de Londrina e Maringá, Estado do Paraná, Brasil, suas condições de trabalho, situações de risco e ocorrência de acidentes de trânsito, foi realizado um estudo transversal por meio de um questionário auto-aplicável, com coleta de dados em 2005/2006. Foram pesquisados 377 motoboys em Londrina e 500 em Maringá, com idade média, respectivamente, de 28 e 29 anos. Houve maior proporção, em Londrina, de trabalhadores com ganho por produtividade, que trabalhavam durante dia e noite ou à noite e com jornada diária superior a dez horas $(p<0,05)$. Apesar da maior exposição dos motociclistas de Londrina a más condições de trabalho e a situações de risco no trânsito, não houve diferença significativa entre as taxas de acidentes relatados nos 12 meses anteriores à pesquisa em Londrina e Maringá (2,89 e 2,80 por 100 pessoas-mês, respectivamente). Este estudo evidenciou precárias condições de trabalho, alta exposição de motoboys a situações de risco no trânsito e elevadas taxas de acidentes envolvendo esses profissionais.

Motocicletas; Acidentes de Trânsito; Acidentes de Trabalho

\section{Referências}

1. Instituto de Pesquisa Econômica Aplicada. Impactos sociais e econômicos dos acidentes de trânsito nas aglomerações urbanas brasileiras: relatório executivo. Brasília: Ministério do Planejamento, Orçamento e Gestão; 2003.

2. Souza ER, Minayo MCS, Malaquias JV. Violência no trânsito: expressão da violência social. In: Secretaria de Vigilância em Saúde, Ministério da Saúde, organizador. Impacto da violência na saúde dos brasileiros. Brasília: Ministério da Saúde; 2005. p. 280-301.

3. Reis MC, Camargo JM. Desemprego dos jovens no Brasil: os efeitos da estabilização da inflação em um mercado com escassez de informação. Brasília: Instituto de Pesquisa Econômica Aplicada; 2005. (Texto para Discussão, 1.116).

4. Chahad JPZ. Tendências recentes no mercado de trabalho: pesquisa de emprego e desemprego. São Paulo Perspect 2003; 17:205-17.

5. Wünsch Filho V. Reestruturação produtiva e acidentes de trabalho no Brasil: estrutura e tendências. Cad Saúde Pública 1999; 15:41-51.

\section{Colaboradores}

D. W. Silva, D. A. Soares e S. M. Andrade foram responsáveis pelo delineamento da pesquisa, coordenação da coleta e análise de dados em Londrina e redação do artigo. D. F. P. P. Soares e T. A. F. Mathias coordenaram a coleta e análise de dados em Maringá e contribuíram na fase final de redação do artigo.

\section{Agradecimentos}

Ao Departamento de Ciência e Tecnologia (DECIT)/Secretaria de Ciência, Tecnologia e Insumos Estratégicos (SCTIE) / Ministério da Saúde e ao Conselho Nacional de Desenvolvimento Científico e Tecnológico (CNPq) pelo apoio financeiro (CT-Saúde/CNPq 24/2004 - processo 505.875/2004-7).
6. Andrade SM, Mello-Jorge MHP. Características das vítimas por acidentes de transporte terrestre em município da Região Sul do Brasil. Rev Saúde Pública 2000; 34:149-56.

7. Bastos YGL, Andrade SM, Soares DA. Características dos acidentes de trânsito e das vítimas atendidas em serviço pré-hospitalar em cidade do Sul do Brasil, 1997/2000. Cad Saúde Pública 2005; 21:815-22.

8. Soares DFPP, Barros MBA. Fatores associados ao risco de internação por acidentes de trânsito no Município de Maringá-PR. Rev Bras Epidemiol 2006; 9:193-205.

9. Queiroz MS, Oliveira PCP. Acidentes de trânsito: uma visão qualitativa no Município de Campinas, São Paulo, Brasil. Cad Saúde Pública 2002; 18:1179-87.

10. Barros AJD, Amaral RL, Oliveira MSB, Lima SC, Gonçalves EV. Acidentes de trânsito com vítimas: sub-registro, caracterização e letalidade. Cad Saúde Pública 2003; 19:979-86. 
11. Ordem dos Advogados do Brasil-Secção São Paulo. Decreto municipal no 41.305 , de 29 de outubro de 2001: dispõe sobre o serviço de transporte de pequenas cargas mediante a utilização de motocicletas, denominado moto-frete, e dá outras providências. http://www2.oabsp.org.br/asp/clipping_jur/ ClippingJurDetalhe.asp?id_noticias $=11504 \& \mathrm{t}$ exto $1=$ moto - frete\&texto $2=\#$ (acessado em 07/ Mar/2008).

12. Prefeitura do Município de João Pessoa. Prefeitura de JP regulariza a atividade de moto-frete. João Pessoa. http://www.joaopessoa.pb.gov.br/ noticias/?n=2245 (acessado em 29/Jun/2006).

13. Diniz EPH. As condições acidentogênicas e as estratégias de regulação dos motociclistas profissionais: entre as exigências de tempo e os constrangimentos do espaço [Dissertação de Mestrado]. Belo Horizonte: Departamento de Engenharia de Produção, Universidade Federal de Minas Gerais; 2003.

14. Diniz EPH, Assunção AA, Lima FPA. Prevenção de acidentes: o reconhecimento das estratégias operatórias dos motociclistas profissionais como base para a negociação de acordo coletivo. Ciênc Saúde Coletiva 2005; 10:905-16.

15. Veronese AM. Motoboys de Porto Alegre: convivendo com os riscos do acidente de trânsito [Dissertação de Mestrado]. Porto Alegre: Universidade Federal do Rio Grande do Sul; 2004.
16. Veronese AM, Oliveira DLLC. Os riscos dos acidentes de trânsito na perspectiva dos moto-boys: subsídios para a promoção da saúde. Cad Saúde Pública 2006; 22:2717-21.

17. Reeder AI, Chalmers DJ, Langley JD. The risky and protective motorcycling opinions and behaviours of young on-road motorcyclists in New Zealand. Soc Sci Med 1996; 42:1297-311.

18. Bohle P, Quinlan M, Kennedy D, Williamson A. Working hours, work-life conflict and health in precarious and "permanent" employment. Rev Saúde Pública 2004; 38 Suppl:19-25.

19. Lardelli-Claret P, Jiménez-Moleón JJ, Luna-delCastillo JD, García-Martín M, Bueno-Cavanillas A, Gálvez-Vargas R. Driver dependent factors and risk of causing a collision for two wheeled motor vehicles. Inj Prev 2005; 11:225-31.

20. Lin MR, Chang SH, Huang W, Hwang HF, Pai L. Factors associated with severity of motorcycle injuries among young adult riders. Inj Prev 2003; 41:783-91.

21. Andrade SM, Mello Jorge MHP. Acidentes de transporte terrestre em município da Região Sul do Brasil. Rev Saúde Pública 2001; 35:318-20.

22. Scalassara MB, Souza RKT, Soares DFPP. Características da mortalidade por acidentes de trânsito em localidade da Região Sul do Brasil. Rev Saúde Pública 1998; 32:125-32.

Recebido em 11/Dez/2007

Versão final reapresentada em 18/Mar/2008

Aprovado em 03/Abr/2008 